\title{
Oral Portfolio in Spanish as a Third Language: Harnessing the Potential of Self- and Peer- Assessment
}

\author{
Pierre-Luc Paquet \\ Language Department, University of Guanajuato, Guanajuato, Mexico
}

\author{
Sara Downs \\ Department of Modern Languages and Translation, University of Quebec at Trois-Rivieres, Trois-Rivieres, Canada
}

\begin{abstract}
Even though research in second language acquisition has demonstrated the importance of oral production and interaction, there is a growing tendency toward distance learning. Therefore, in order to include oral practice and evaluation in an online course, a new pedagogical tool was designed, namely the oral portfolio. This article describes and analyzes an oral portfolio which included learner production and self- and peer-assessment. Combining these aspects provided data on both linguistic and metalinguistic abilities. The results revealed a relationship between oral competency and self- and peer-assessment abilities, suggesting a beneficial role of metalinguistic reflection in the development of oral communication skills. Moreover, this study explored how self- and peer-assessment could be better implemented in a language course. Based on the observations gathered throughout the study, we believe that learners need to be trained and to develop the formative assessment competency, in order to maximize the benefits, for assessment to be as sustainable as possible.
\end{abstract}

Index Terms - oral portfolio, metalinguistic reflection, self- and peer-assessment, online/distance learning, Spanish as a third language

\section{INTRODUCTION}

Over the last decades, learner involvement, reflection and independence have taken on a growing importance in the field of language education. Few teachers will disagree with the importance of helping language learners gain in independence, but there remains a good deal of uncertainty about applications for language education. Dickinson (1992) "associates independence with active responsibility for one's own learning" (cited in Benson \& Voller, 2013, p. 2). This is a problematic concept because it carries meaning that can be applied differently depending on particular circumstances of language education. For instance, we explore learners' independence from an online computermediated Spanish as a third language university course and observe the link between metalinguistic reflection and oral production competency in language learning using an oral portfolio including a self- and peer-assessment. More specifically, the current research project describes the use of an oral portfolio and a self- and peer-evaluation in the development of oral competency. With the exception of Woll and Paquet (2017), we cannot recall any mention in the literature of the use of self- and peer-assessment specifically on oral competency.

The use of computer-mediated communication (CMC) to facilitate language learning has become commonplace in both face-to-face and distance learning, given its various affordances (see for example Thorne, 2008). CMC appeals to a broad language learning audience due to its perceived connections to 'real life' and contributes to the development of many features of language learning, including authentic language use, target language production and target form use (Thorne, 2008). That said, CMC does have its specific limitations, especially in regard to the challenge of observing oral competency in an online setting (Woll \& Paquet, 2017; Lin, 2014). In light of a decade worth of second language acquisition (SLA) research emphasizing the need for maximum learner involvement in order for acquisition to occur, combined with the abovementioned constraint of CMC, our investigation explores the use of an oral portfolio, such as the one used in Woll \& Paquet (2017), with the addition of a combined self- and peer-evaluation. This brings us to investigate not only the implementation of a pedagogical intervention, the oral portfolio to observe oral competency in a CMC course, but also to explore the potential benefit of metalinguistic reflection with regard to oral communication skills (Genesee, Lindholm-Leary, Saunders \& Christian, 2005; Woll \& Paquet, 2017; Tsang, 2017).

\section{BACKGROUND}

Various researchers suggest that the practice of metalinguistic reflection in the language classroom encourages and maximizes second language development (eg. Swain, 1995; Simard, French \& Fortier, 2007; among others). Moreover, they consider metalinguistic reflection to be an observable manifestation of language awareness and define it "as any 
conscious act of reflection about language, including learners' planning of how they will process it linguistically" (Simard, French \& Fortier, 2007, p. 510). According to Bialystok (2001), "metalinguistic awareness implies that attention is actively focused on the domain of knowledge that describes the explicit properties of language" (pp. 126127). In other words, a prerequisite to metalinguistic reflection is attention. Moreover, as stated by Woll \& Paquet (2017), "the more occasions learners have to reflect on the language, the more they become aware of their own learning process, allowing them to better adapt to different kinds of communicative situations" (p. 99). Alternatives to promoting reflection and metalinguistic reflection are self- and peer-assessment, which further learners involvement and critical thinking. Combining them into a portfolio format should allow learners to demonstrate critical analysis and reflectivity about the language itself and the materialization of language learning achievements.

Even before any student involvement takes shape, the task of planning content and assessment sits squarely with the teacher. Subsequently, as teachers assess learners' performance and/or knowledge related to the given subject, the acquisition of curricular-specific content for the sake of the course is foremost in their mind, but teachers also want learners to be prepared for what comes next, and to relate their teaching to what learners are going to experience in the real world. From this point of view, Boud \& Soler (2016) state that one of the major questions in higher education is "[...] whether educational provision equips learners effectively, not just for immediate educational requirements, [...] but also for whether it prepares them for what might be required in the future whether that be in educational institutions or beyond" (p. 401). In keeping with the abovementioned, Boud \& Soler (2016) suggest that teachers should provide learners with opportunities to develop their informed judgment. Here, we choose to highlight a number of Boud \& Soler's (2016) suggestions as they relate the present study. As previously mentioned, learner involvement plays a crucial role in language development, and equates with active learning, which is observed by way of commitment and the level of reflexivity. More importantly, learners should be aware of their own level of knowledge and the resulting gaps in order for them to set realistic goals.

In other words, to make learning significant and lifelong, and to develop the learners reflective practice, which is defined as sustainable assessment, must be put forth, namely using pedagogical tools such as self- and peer-assessment. These two are promising alternatives, with benefits such as helping learners reflect on their own progress and so, at different stages of learning. Indeed, self- and peer-assessment research is well documented in the field of second language education (eg. Boud \& Soler, 2016; Wanner \& Palmer, 2018; Magin, 2001; Osmond, Merry \& Reiling, 2000; among others). The potential of self- and peer-assessment will be further discussed in the following sections.

\section{Self-assessment as a learning tool}

Andrade \& Du (2007) define self-evaluation as a:

process of formative assessment during which students reflect on and evaluate the quality of their work and their learning, judge the degree to which they reflect explicitly stated goals or criteria, identify strengths and weaknesses in their work, and revise accordingly. (p. 160)

In other words, this process is a way of increasing learners' involvement in their own learning by having them make judgments about their achievements and outcomes. Moreover, in order for self-assessment to be effective, learners need to first learn how to develop their critical thinking, which occurs over time (cf. Dochy, Sluijsmans, \& Segers, 1999; Mogessie, 2017).

The use of self-evaluation in the classroom primarily benefits the learner, who is the main decision maker in the process. For their part, teachers are able to share responsibility for the learning and teaching process with each of their students. Based on Spiller (2012), there are many advantages in using self-assessment as a learning tool, which can be divided into three broad categories: The first broad category relates to recognition-based reflection. By using this strategy, learners build on their learning after taking stock of what needs to be learned. This actually encourages learners' reflection on their own learning and pushes them to set realistic goals for themselves in terms of "where to go next". The second category concerns taking responsibility for learning, including the development of independence on the part of the learner. Moreover, this pedagogical tool inspires learners to take an active part in their own learning, as well as to promote a learning partnership instead of a compulsory assignment imposed by the teacher. In addition, it provides learners with the formative aspects of assessment, which makes them more reflective about the language, which was previously defined as metalinguistic awareness. Ultimately, the use of self-assessment allows learners to develop a competency which will help them beyond the classroom. The third and final category relates to inclusionary partnership, or how self-assessment is reflective of learner background, experience and readiness. Furthermore, selfassessment aligns with the recent paradigm shift away from teacher-centered performance in favour of a more studentcentered model. (see also Wanner \& Palmer, 2018; Chen, 2010; Boud \& Soler, 2016)

Implementing self-evaluation requires the consideration of several elements, including a clear rationale, explicit procedures, reassurance of a safe environment, and the confidence that other students will do likewise (Boud \& Falchikov, 2007; Wanner \& Palmer, 2018; among others). Students should be aware of the assessment criteria, and be absolutely clear about the standards of work expected.

Peer-assessment as a learning tool

In the first version of the current study written by Woll \& Paquet (2017), numerous conference participants mentioned the value of adding a peer-assessment to the equation. Peer-assessment is a classroom-based collective and evaluative strategy, which involves one or more students providing feedback to other students on a task. According to 
Falchikov (2007) peer-assessment "requires students to provide either feedback or grades (or both) to their peers on a product or a performance, based on the criteria of excellence for that product or event which students may have been involved in determining" (p. 132). However, it is sometimes difficult to predict the fairness and the accuracy of the learners' judgment, which explains why peer-assessment necessitates constant innovation and improvement in the way it is implemented (cf. O'Toole, 2013). Moreover, according to Hanrahan \& Isaacs (2001), formative assessment is not taken seriously and students find it too time consuming since no mark is attached. To prevent these situations from happening, the combination of self- and peer-assessment used not only as formative but also as summative assessment is highly recommended.

Peer-assessment has many advantages including student involvement, authentic feedback and the opportunity for metalinguistic reflection. To ensure the quality of peer assessment, Tillema, Leenknecht \& Segers (2011) outlined three criteria that must be present in order for the assessment process to be meaningful: Authenticity (actively engaging students), transparency (clear and precise instructions) and generalisability (the outcome can be generalised to other tasks). More specifically, peer-assessment allows learners the opportunity to clarify, review and edit their thoughts, which will be enhanced with time and practice.

The principles of implementation of peer-assessment are basically the same as those for self-assessment. Taking all of the above into consideration, it is necessary to acknowledge the benefits of learners involvement, ability to reflect and analyse their learning process and capacity to set realistic goals, which would fill their knowledge gap. More specifically, these tools create a distance between the classic, teacher-centred summative assessment tools where learning was measured quantitatively without any input relevant to the progression of learning. In essence, portfolio and self- and peer-assessment is a sustainable assessment method that promotes independent and autonomous learning.

\section{STATEMENT OF THE PROBLEM}

The present contribution aims to provide a comprehensive description of the oral portfolio and its implementation in an advanced Spanish course at the university level, which was taught in a computer-mediated communication format. Moreover, this study seeks to establish the usefulness of this assessment tool in the measurement of oral competency. Subsequently, learners submitted a self- and peer-assessment of their oral portfolio. The resulting summative assessment aimed at providing insights on the learners evaluating and not on the evaluees, which affords a vantage point in regard to the development of their metalinguistic knowledge. Therefore, this study attempts to shed light on the potential benefits of these pedagogical interventions in the L3 learning process. To sum up, the objectives of this article are:

(1) To explore the relationship between oral production competency and level of metalinguistic awareness.

(2) To describe the oral portfolio assessment tool in the development of learners' oral competency;

(3) To explore how to best implement metalinguistic reflection within a self- and peer-evaluation in an advanced Spanish as a third language university course.

This research project, which is outlined in the following sections, is characteristic of classroom-based research in that the resulting observations are descriptive in nature.

\section{MEthodology}

\section{Participants}

Given the importance of having the students engaged in their own learning process and to develop their L2 metalinguistic knowledge, as mentioned in the preceding section, an oral portfolio was designed and implemented to 25 Spanish L3 learners. The observations, which are described in this study, were gathered during the fall semesters of $2015^{1}$ and 2017. At the end of the course, students in the 2015 group completed a self-evaluation of their portfolio whereas in 2017, a peer-evaluation was added to the assignment. All participants in the project were enrolled in either an online or a hybrid ${ }^{2}$ advanced Spanish course at a Quebec university. The participants (17 females, 8 males) were enrolled in two broad areas of study: translation $(n=13)$ and second language education $(n=9)$, in addition to three non-program students. With the exception of three (3) graduate students, the majority $(\mathrm{n}=22)$ were pursuing a bachelor's degree. They all met the requirements to take this course and were ranked as advanced learners of Spanish. Table 1 specifically illustrates the learners' proficiency level, term of study, program of study and learning context.

\footnotetext{
${ }^{1}$ Data gathered in 2015 were previously published as proceedings from the Meeting on Language Teaching by Woll \& Paquet (2017).

${ }^{2}$ This project was conducted through three different learning contexts: (1) online exclusively, (2) hybrid including 14 hours of online oral workshops using a virtual classroom platform, and (3) hybrid including 22 hours of classroom oral workshops.
} 
TABLE 1:

BACKGROUND INFORMATION FOR THE L3 LEARNERS OF SPANISH

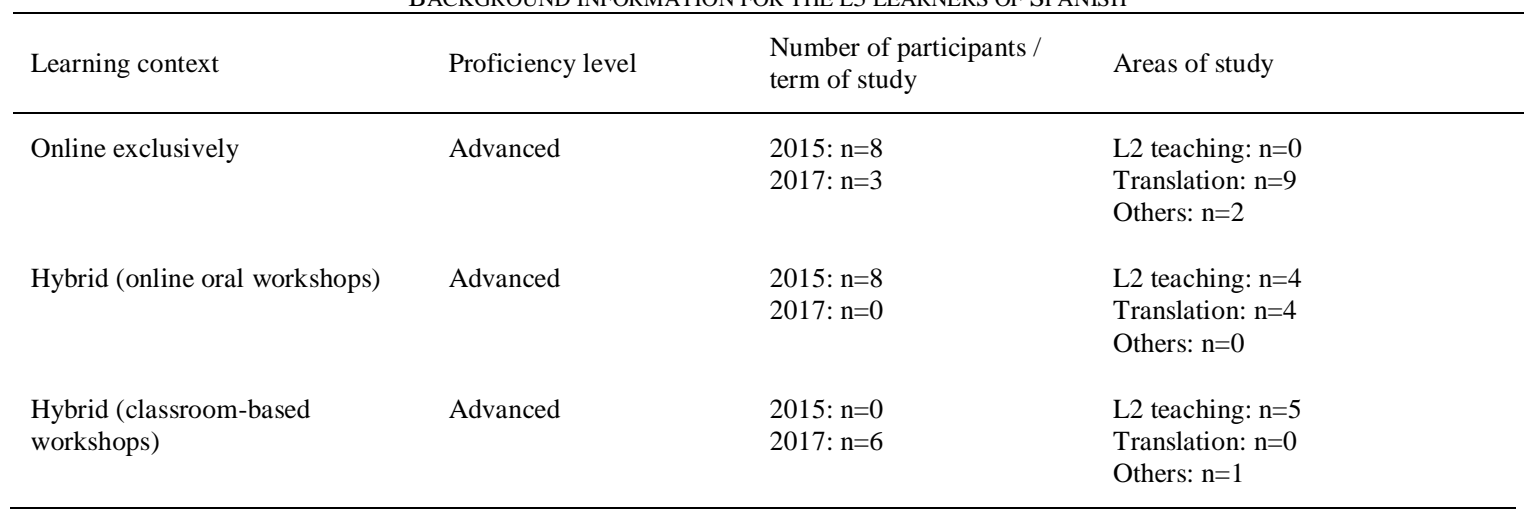

As can be seen in Table 1, the majority of learners come from two broad areas of study, namely translation and teacher education. Therefore, instrumental motivation to learn Spanish, not only from a practical point of view, but more importantly from a metalinguistic standpoint, is seemingly foremost in their approach to learning Spanish. As for the other three students, their motivation could have arisen from a variety of sources, but they were nonetheless rounding out their usual face-to-face program with an online learning format.

\section{Implementation}

For this research project, one methodological constraint was that the course Advanced Spanish was taught and administered in a computer-mediated communication format. Consequently, we needed to develop an observation tool to (1) assess participants' oral communication skills, (2) record their production on a user-friendly platform that would be easy to access for both participants and researchers, and (3) measure their development of metalinguistic knowledge. Although there are many different platforms that could have been used, we decided to use Facebook, which participants were already familiar with. For confidentiality purposes, participants were required to create a Facebook page specifically for the course.

The oral portfolio consisted of four oral entries on topics related to current affairs for the students enrolled in the 2015 course or related to the units from the Spanish textbook C de C1 (Acquaroni et al., 2017) for the 2017 students. Participants had one week to read on the topic, develop their argument and prepare a response. The participants in the hybrid course format developed their argument during the workshops and were asked to refer back to their group discussion, whereas the participants from the online exclusively format were requested to find information from various sources and reference it in their oral production. At the end of the week, they needed to record a video comment and upload it onto their Facebook page. Learner productions were assessed and analyzed for breadth of vocabulary, content (argumentation), grammatical accuracy and fluency in line with the linguistic objectives of the modules.

\section{Self-assessment ${ }^{3}$}

Each participant, from both terms of study, completed a self-assessment at the end of the course. Learners had to go back to their oral portfolio entries and listen to them carefully. This self-assessment took into consideration three main aspects, which will be described in the following paragraphs: (1) general impression of their language abilities, (2) sensitivity to violations of grammatical concepts, and (3) ability to set realistic goals. While all of these were aimed at involving participants in their own learning process, the second aspect also provided the instructor with a trace of what learners actually knew about the language in relation to how they used it.

First of all, to share their general impression of their abilities, learners had to respond to two descriptors aimed at self-assessing their fluency and their breadth of vocabulary. Since students were experienced L2 learners, the descriptors were written in Spanish. They were formulated to leave the participants room to provide an extensive overview of their performance and reflected the self-assessment scales of the CEFR listed below.

- (1a) I can present clear, detailed descriptions of complex subjects integrating sub-themes, developing particular points and rounding off with an appropriate conclusion. (Council of Europe, 2001, p. 27)

- (1b) General: I can express myself fluently and spontaneously, almost effortlessly. Only a conceptually difficult subject can hinder a natural, smooth flow of language. (Council of Europe, 2001, p. 28)

The second aspect to be self-assessed was related to another important component of the course, which required learners to analyse the grammatical accuracy of their language production. By adding the self-assessment to this course objective, participants had to analyze their grammatical accuracy, notice their strengths and weaknesses and further examine how the language works after extracting positive and negative evidence from their portfolio. As for the negative evidence, participants were asked to provide the source of the error and to correct it with proper Spanish.

Finally, with regard to the third aspect, learners had to set realistic goals for the future. More specifically, participants had to conclude their portfolio stating what concepts they believed were acquired entirely, and what concepts were only partially acquired and needed more work.

\footnotetext{
${ }^{3}$ This section is widely taken from Woll \& Paquet (2017).
} 
In the 2015 term of study, students were asked to submit a written self-assessment as well as an oral one, which was uploaded into their portfolio. Whereas quality, accuracy and depth of reflection were rated with respect to the learners' production, the instructor also evaluated the quality of the language used in the self-assessment. The latter was of the greatest interest since the way they expressed themselves in their self-assessment sometimes contradicted their analysis. In turn, participants whose projected goals mirrored their stage of development (in that their goals were realistic) were identified as independent learners, even if they lacked certain linguistic skills. As for the 2017 term of study, learners only completed a written self-assessment because of time constraints.

\section{Peer-assessment}

Each participant from the 2017 term of study completed a peer-assessment of one of their classmates at the end of the course. Learners were asked to visit the oral portfolio of a classmate, to listen carefully to the entries and evaluate their language use. Learners were told, right from the beginning, that this practice would not affect their peers' final grade in any way and that this task was only used to assess the evaluators' metalinguistic reflection and their level of Spanish. The peer-assessment took into consideration three main aspects, which will be described in the following paragraphs: (1) critical and constructive reflection on their classmate's language abilities, (2) grammatical control and peer correction, and (3) specific language use. For each aspect, learners needed to rate their classmate's performance on a scale from one to five. While all of these were aimed at involving learners in their own learning process, the second and third aspects also provided the instructor with a trace of what learners actually knew about the language and of their level of metalinguistic awareness.

First of all, to reflect and share their constructive criticism of their classmate's portfolio entries, learners had to respond to two descriptors aimed at peer-assessing fluency and coherence. As in the self-assessment, the descriptors were written in Spanish. Additionally, descriptors were formulated to leave the evaluator room to provide an extensive overview of their classmate's performance.

- (2a) Fluency: My classmate "can express him/herself fluently and spontaneously, almost effortlessly. Only a conceptually difficult subject can hinder a natural smooth flow of language" (Council of Europe, 2001, p. 28).

- (2b) Coherence: My classmate "can produce clear, smoothly flowing, well-structured speech, showing controlled use of organisational patterns, connectors and cohesive devices" (Council of Europe, 2001, p. 28).

The second aspect to be peer-assessed was related to another important component of a language course: lexical and grammatical accuracy, and self-correction. Student-evaluators were asked to assess their classmates' accuracy and ability to self-correct their mistakes. For each entry, they needed to select some positive and negative evidence of language use and to analyse it. The main objective of this aspect was to observe the evaluator's level of metalinguistic awareness and reflection. In order to correct their classmate's production, they needed to be aware and to notice the incongruencies in the entries. More specifically, student-evaluators needed to rank their classmate on a scale from one to five based on the following descriptor:

- (3) Accuracy: My classmate "consistently maintains a high degree of grammatical accuracy; errors are rare, difficult to spot and generally corrected when they do occur" (Council of Europe, 2001, p. 28).

With regard to the third aspect, student-evaluators were provided with a grid where they were asked to take some parts of the production, transcribe them and analyse them. Concretely, they needed to analyse their classmate's portfolio production taking into consideration the following elements: breadth of vocabulary, grammatical accuracy, spontaneity and content. At the end of this section, student-evaluators had to state the strengths and weaknesses of their classmate according to their analysis.

\section{Scoring}

As previously stated, the oral portfolios were analyzed with respect to four aspects of oral competency, namely vocabulary, content, accuracy and fluency. However, since fluency was potentially influenced by the learners preparation for the task, this aspect was not considered in the present study, so that results obtained would be largely comparable. Each of the four independent entries was globally assessed with respect to descriptors, taking into account the remaining three aspects mentioned above. Letter grades were assigned for each portfolio entry based on the levels of attainment. These were then converted into percentages based on the departmental scale. As for the self- and peerassessment, the evaluation was based on the above-mentioned criteria.

In the following section, we describe the results and observations of the assessment tool put forth. We first take a look at the relationship between learners' oral competency and their capacity for metalinguistic reflection, using selfand peer-assessment as a starting point. Subsequently, we share our observations on the use of self- and peer-assessment.

\section{RESUlTS AND DisCUSSION}

The first part of this section explores the relationship between oral production competency and level of metalinguistic awareness, which corresponds to our first research objective. The overall results of oral performance ranged from $48 \%$ to $100 \%$ and self- and peer-assessment ${ }^{4}$ scores were between $45 \%$ and $100 \%$. As illustrated in Table 2 , means and standard deviations for both measures were also largely comparable, suggesting that both types of performance might be in some way related to each other.

\footnotetext{
${ }^{4}$ For the sake of combining 2015 and 2017 terms of study, results from the 2017 term of study self- and peer-assessment were averaged.
} 
TABLE 2:

ORAL COMPETENCY AND SELF-ASSESSMENT SCORES

\begin{tabular}{lllll} 
& Min $(\%)$ & Max $(\%)$ & Mean $(\%)$ & $S D$ \\
\hline Oral competency & 48 & 100 & $84.6 \%$ & 0.14 \\
Self-assessment & 45 & 100 & $81.8 \%$ & 0.15 \\
\hline
\end{tabular}

A closer look at the individual scores obtained on each measure provides further support for this assumption. However, two learners seemed to contradict this tendency. On one hand, there is a learner from the 2015 term of study who failed to comply with the deadlines and requirements for the portfolio assignment, which greatly affected his overall oral competency mark. Similarly, a learner from the 2017 term of study admitted to not having invested the time and effort to submit a thorough and effective self and peer assessment.

This study does not include the sample size nor the statistical power to suggest the presence of a relationship between oral competency and level of metalinguistic awareness with certainty. However, in view of an exploratory interpretation of the results, the scatterplot in Figure 1 demonstrates the potential tendency toward the above mentioned relationship.

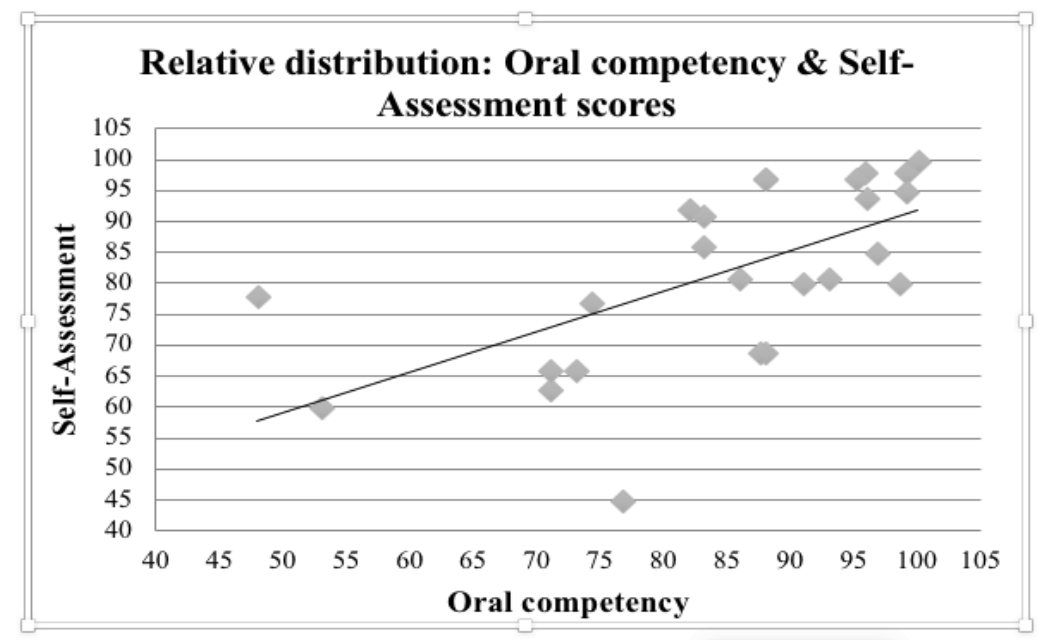

Figure 1: Relationship Between Self-Assessment And Oral Competency Scores

As illustrated in Figure 1, despite the heterogeneous make up of the participants in this study, learners who scored high on oral competency generally also attained high self-assessment scores. This was confirmed by statistical analyses, which revealed a strong correlation (Pearson's $r=.615, p=0.002$ ). In summary, our results indicate that the type of oral skills targeted in the oral portfolio is positively in line with the nature of metalinguistic reflection skills developed in the self- and/or peer-assessment.

Based on the results gathered in Woll \& Paquet (2017) and the ones from this research project, there may be different ways of interpreting the data previously presented. According to Woll \& Paquet (2017), "advanced L2 learners in an academic setting have already acquired a set of analytic skills enabling them to reflect on different target language uses, and therefore able to judge their own production in a critical manner" (p. 96). Moreover, as previously mentioned in Tillema et al. (2011), in order to have quality of feedback and analysis, learners must develop quality criteria, such as generalisability, which makes transfer across any task possible. Generalisability would support the premise that advanced learners have previously accessed reflective skills which enable them to apply the latter to any learning condition. For our part and taking the above into consideration, we posit that self- and peer-assessment may help our language learners notice and become aware of Spanish syntactic structures. More specifically, we believe that metalinguistic awareness may be the impetus for their ongoing oral competency development.

The second objective of the current study was to describe the oral portfolio assessment tool in the development of learners' oral competency. Recall that one of the main challenges specific to CMC in a second language learning reality is the means of including an oral competency requirement, which was an imperative in the given context. The authenticity of the portfolio content as an incentive for student involvement and progress is also worthy of mention. In the 2015 version of the course, some of the current issues examined included endangered languages and the plight of Syrian refugees, both of which were highly visible headlines at the time. In the same fashion, the 2017 term of study included themes from Acquaroni et al. (2017) such as the use of seduction in publicity and cultural stereotypes. For their respective use in each of the two course iterations, both series of topics aimed to elicit student willingness to explore the topics in-depth.

Moreover, the tripartite combination of evaluated elements, namely, fluency of speech, accuracy of speech in terms of the unit's and the course's grammatical objectives, and breadth of specific vocabulary related to the task gave 
students ample opportunity to develop and perfect the recognized hallmarks of oral competency. An additional strength of the portfolio is that learners received direct feedback throughout the entire semester, which they could proceed to implement in the form of improvements to the subsequent oral portfolio entry. From a teaching perspective, the use of the oral portfolio tool was advantageous because the trace of any progression was evident over time, i.e. the entire semester. This last aspect is especially helpful in providing a global assessment. With the growing movement toward online and distance learning, the use of an assessment tool such as the oral portfolio, breaks down some of the barriers both teachers and learners previously experienced in regard to oral competency.

Ultimately, with the addition of a self- and peer-assessment at the end of the semester, this platform afforded learners the opportunity to become aware of the gaps in their learning. More specifically, as learners were listening and commenting both their own and their classmate's portfolio, they were confronted with positive and negative evidence of Spanish use. For some learners, the resulting inquiry would be sufficient for them to construct a more accurate oral production. Although this last benefit can only be considered as a possible contributing factor, the process may nonetheless have positive repercussions on their oral competency.

In keeping with the abovementioned, the third and final goal of the present study was to explore how to best implement metalinguistic reflection within a self- and peer-evaluation in an advanced Spanish as a third language university course. It is a useful way for learners to examine their overall proficiency and to reflect on their language related knowledge. As results from the first research objective have shown, learners with higher oral competency also demonstrate higher metalinguistic awareness. A learner from the 2017 term of study thought it appropriate to include a comment at the end of the assignment:

¡Muchísimas gracias Pierre-Luc, este ejercicio de reflexión metalingüística permitió que me diera cuenta de algunos de mis puntos débiles, que son bastantes! [Thank you Pierre-Luc, this metalinguistic reflection exercise allowed me to notice some of my weaknesses, which are numerous!]

This comment demonstrates the impact of self- and peer-assessment on metalinguistic reflection. This learner, who is a highly proficient speaker of Spanish, showed the ability to reflect in a metalinguistic manner in regard to the perceived weaknesses. The learner's perceived strengths were related mainly to the macro-text features (content, structure of the talk, etc.), which could be explained by the more traditional idea of assessment where teachers mainly focused on learners' weaknesses. This said, as stated by Mogessie (2017), learners still need to be trained and to develop the formative assessment competency, in order to maximize the benefits, even in the case of highly proficient language learners.

Using and observing the self- and peer-assessment led us to a question for future research: Is one of the tools more pertinent or more constructive than the other? Based on numerous observations from the present study, learners' assessment seemed to be more relevant for their peer-assessment than their self-assessment. This could be explained by different factors such as a figurative "blind spot" in self-assessment. In essence, learners may need to turn their focus to peer-assessment in order to better perceive their own gaps, which in turn makes self-assessment more proficient. It may prove interesting to compare self-assessment to peer-assessment because in the latter, learners serve as consultants, and therefore may be less anxious about being either judged or perceived as irrelevant. Consequently, to achieve the optimal metalinguistic reflection, one should consider using both self- and peer-assessment in order to fulfill the training and the reflective need of a deeper and more relevant reflection.

Taking into consideration everything put forth in the current study, we nonetheless must return to the essence of what Boud \& Soler (2016) mention as the main takeaways of self- and peer-assessment, namely, learner involvement and commitment, active learning and reflexivity, and awareness of the gaps in knowledge. When teachers mobilize all three with the express purpose of developing informed judgement and sustainable assessment in their students, they contribute to learners' independence and lifelong learning.

\section{CONCLUSION}

In this paper, we have juggled with many suggestions and interpreted many observations, which could be considered as subjective. However, the main aspect to mention is the importance of having our learners involved in their own learning process. Learning through CMC may not be the optimal way for language development. However, if the course integrates the development of oral competency through a tool such as the oral portfolio, and affords learners with the opportunity to develop linguistic knowledge by means of metalinguistic reflection such as self- and peer-assessment, we manage to have independent learners, who are involved and committed in their learning process.

There are some limitations in the current study, such as the lack of training in the use of self- and peer-assessment or emphasis on the use of metalanguage in sustainable assessment. That being said, there is a need for future research into sustainable assessment in the field of second language development. More specifically, future research should tap into how to develop learners' ability to judge, reflect and think critically. By doing so, learners would be better prepared to self-assess their third language performance and therefore concentrate on bridging the gap in their knowledge. Another limitation relates to the assessment timeframe, in that self- and peer- assessment only occurred at the end of the semester, after students concentrated on their productions which were uploaded to individual oral portfolios. The selfand peer- assessment process would gain in student involvement through it taking place over the course of the semester. 


\section{REFERENCES}

[1] Acquaroni, R., Amenós, J., González, V., Gras, P., Simkievich, J., Soriano, C., \& Tarrés, I. (2017). C de C1-Libro del alumno. Barcelona: Difusión.

[2] Andrade, H., \& Du, Y. (2007). Student responses to criteria-referenced self-assessment. Assessment and Evaluation in Higher Education, 32(2), 159-181. doi:https://doi.org/10.1080/02602930600801928.

[3] Benson, P., \& Voller, P. (2013). Introduction: autonomy and independence in language learning. In P. Benson \& P. Voller (Eds.) Autonomy \& independence in language learning (pp. 1-12). New York: Routledge.

[4] Bialystok, E. (2001). Bilingualism in development: Language, literacy, and cognition. Cambridge: Cambridge University Press.

[5] Boud, D., \& Falchikov, N. (2007). Rethinking assessment in higher education: Learning for the long term. London: Kogan Page.

[6] Boud, D., \& Soler, R. (2016). Sustainable assessment revisited. Assessment \& Evaluation in Higher Education, 41(3), $400-413$. doi:https://doi.org/10.1080/02602938.2015.1018133.

[7] Chen, C. (2010). The implementation and evaluation of a mobile self- and peer-assessment system. Computer and education, 55(1), 229-236. doi:https://doi.org/10.1016/j.compedu.2010.01.008.

[8] Council of Europe (2001). Common European framework of reference for languages: Learning, teaching, assessment. Cambridge: Cambridge University Press.

[9] Dickinson, L. (1992). Collaboration in Assessment: Empowering the individual course member. In E. Sadtano (Ed.). Language teacher education in a fast-changing world. Singapore: SEAMEO Regional Language Centre.

[10] Dochy, F., Sluijsmans, D., \& Segers, M. (1999). The use of self-, peer- and co-assessment in higher education. Studies in Higher Education, 24(3), 331-350. doi:https://doi.org/10.1080/03075079912331379935.

[11] Falchikov, N. (2007). The place of peers in learning and assessment. In D. Boud, \& N. Falchikov (Eds.) Rethinking assessment in higher education: Learning for the long term (pp. 128-143). London: Kogan Page.

[12] Genesee, F., Lindholm-Leary, K., Saunders, W., \& Christian, D. (2005). English language learners in U. S. schools: An overview of research findings. Journal of Education for Students Placed at Risk, 10(4), 363-386. doi:https://doi.org/10.1207/s15327671espr1004_2.

[13] Hanrahan, S. J., \& Isaacs, G. (2001). Assessing Self- and Peer-assessment: The Students' Views. Higher Education Research \& Development, 20(1), 53-70. doi:https://doi.org/10.1080/07294360123776.

[14] Lin, H. (2014). Establishing an empirical link between computer-mediated communication (CMC) and SLA: A meta-analysis of the research. Language Learning \& Technology, 18(3), 120-147. doi:http://dx.doi.org/10125/44387.

[15] Magin, D. (2001). Reciprocity as a source of bias in multiple peer assessment of group work. Studies in Higher Education, 26(1), 53-63. doi:https://doi.org/10.1080/03075070020030715.

[16] Mogessie, M. (2017). Peer-assessment in higher education - twenty-first century practice, challenges and the way forward. Assessment \& Evaluation in Higher education, 42(2), 226-251. doi:https://doi.org/10.1080/02602938.2015.1100711.

[17] Osmond, P., Merry, S., \& Reiling, K. (2000). The use of student derived marking criteria in peer and self-assessment. Assessment \& Evaluation in Higher Education, 25(1), 23-38. doi:https://doi.org/10.1080/02602930050025006.

[18] O’Toole, R. (2013). Pedagogical strategies and technologies for peer assessment in Massive Open Online Course (MOOCs). Discussion paper, University of Warwick.

[19] Simard, D., French, L., \& Fortier, V. (2007). Elicited metalinguistic reflection and second language learning: Is there a link?. System, 35(4), 509-522. doi:https://doi.org/10.1016/j.system.2007.06.004.

[20] Spiller, D. (2012). Assessment Matters: Self-Assessment and Peer Assessment. New Zealand: Teaching Development, University of Waikato.

[21] Swain, M. (1995). Three functions of output in second language learning. In G. Cook \& B. Seidlhofer (Eds.) Principle and Practice in Applied Linguistics: Studies in Honour of H.G. Widdowson (pp. 125-144), Oxford: Oxford University Press.

[22] Thorne, S. L. (2008). Computer-mediated Communication. In N. H. Hornberger (Ed.) Encyclopedia of language and education (pp. 1415-1426). Boston: Springer.

[23] Tillema, H., Leenknecht, M., \& Segers, M. (2011). Assessing Assessment Quality: Criteria for Quality Assurance in Design of (Peer) Assessment for Learning - A Review of Research Studies. Studies in Educational Evaluation, 37(1), $25-34$. doi:https://doi.org/10.1016/j.stueduc.2011.03.004.

[24] Tsang, A. (2017). Positive effects of a programme on oral presentation skills: high- and low-proficient learners' self-evaluation and perspectives. Assessment \& Evaluation in Higher Education, 43(5), $760-771$. doi:https://doi.org/10.1080/02602938.2017.1407917.

[25] Wanner, T., \& Palmer, E. (2018). Formative self- and peer assessment for improved student learning: the crucial factors of design, teacher participation and feedback. Assessment \& Evaluation in Higher Education, 1-16. doi:https://doi.org/10.1080/02602938.2018.1427698.

[26] Woll, N., \& Paquet, P-L. (2017). Oral portfolio and self-evaluation: Encouraging metalinguistic reflection in university-level learners of Spanish (L3). In B. Zuercher (Ed.) Proceedings of the V Annual Meeting on Language Teaching (pp. 92-104). Montreal: Université du Québec à Montréal.

Pierre-Luc Paquet was born in Quebec, Canada. He completed his doctoral dissertation in Second Language Acquisition at the University of Alicante in Spain. His research interests are anchored in the field of second/third language acquisition and predominantly on the influence of other languages in the acquisition of grammar. Moreover, he is currently working on a research project in crosslinguistic pedagogy. He is a full time professor in Applied Linguistics at the University of Guanajuato, Mexico. 
Sara Downs was born in Stockport, UK. She completed a Master's degree in Applied Linguistics at Concordia University in 2008. Her research interest focuses on written corrective feedback and teachers reflective practices. She is currently a lecturer at the University of Quebec at Trois-Rivieres, teaching courses related to English as a second language teaching. 